it just confirms the clinical diagnosis which was quite obvious, in others, it carries complementary information on the pathology and provides the diagnosis. Repetition of this examination in the same patient leads to the prognosis.

In traumatic paraplegia, electromyography may reveal very rapidly the presence of an intact conus medullaris which is of great interest.

In infants with spina bifida and myelomeningocele, electromyography of the sphincters seems to be probably the best and the most sensitive guide to assess sphincter function, since at this age no other method of investigation is available and the clinical impression may be of little help (Chantraine et al., 1965).

In lower motor neurone lesion, this examination method gives more precision about the localisation of the lesion, When repeated, as it must be, it has its own and full value. It may detect early signs of reinnervation and may give some idea about prognosis.

Therefore, in most patients, electromyography may provide important information leading to rehabilitation of the sphincters. However, further systematic studies should be continued to improve the results and to give electromyography a larger place in the investigative techniques.

\title{
REFERENCES
}

Chantraine, A. Revue neurol. (in press).

Chantraine, A., Lloyd, K. \& Swinyard, C. (1965). F. Urol. 95, 250.

Petersen, I. \& Franksson, S. (1955). Brit. f. Urol. 27, I 48.

Timmermans, L., Diverse, P. \& Chantraine, A. (I964). Acta urol. belg. 32, 425.

\section{THE PHYSIOLOGY AND PATHOPHYSIOLOGY OF CONSTIPATION}

\author{
By A. M. Connell, B.Sc., M.R.C.P. \\ Lecturer in Clinical Science, Department of Surgery, Queen's University, Belfast
}

THIs paper presents a review of some recent work on the physiology of the colon which has led to a more rational approach to the troublesome symptoms of constipation.

I. Bowel Habit of a Normal Population. The term 'constipation' refers to both infrequent defaecation and undue difficulty in defaecation. This latter is subjective and cannot be measured, but definite limits of bowel frequency have been determined.

While it is generally believed that normal persons have approximately one bowel action a day, it is sometimes inferred that there is virtually no limit to the number of bowel actions that a normal person may have. Thus, one standard text seems to imply that all frequencies from 14 times per day to once per year are normal (Keele \& Neal, I96I). However, a recent survey conducted jointly in a general practice and an industrial community has helped to define the bowel habits of a normal community (Connell et al., 1965). This survey has shown that 
88.5 per cent. of a normal working community have a frequency range from 5 to I 4 bowel actions per week. More interesting is that in this survey only I per cent. of the population had bowel habit outside the range of 3 bowel actions per week to 3 per day. There was no marked change in the bowel habit with age or any clear difference between the sexes.

2. Transit through the Colon. Studies using crude markers such as carmine or charcoal and more quantitative methods using radio chromium have indicated great differences in the rate of transit through the colon in normal subjects. Using radio active chromium $\left(\mathrm{C}_{51}\right)$, Hansky and Connell (I962) showed that the transit time through the alimentary tract of normal subjects could be as long as 7 days and that the main bulk of an injected dose of marker might not be passed for II 7 hours. By far the greatest time in transit is due to passage through the colon, as passage through the stomach and small intestine seldom takes longer than 12 hours.

The main sites of accumulation of faeces appear to be the ascending colon and the sigmoid. This was confirmed in a study of straight X-rays of the abdomen taken in patients about to have an intravenous pyelogram but who had not had any preliminary bowel preparation. Films from patients with digestive symptoms were excluded from the study. The faecal loading of the different parts of the colon was scored as $\mathrm{O},+$, or ++ by each of two observers. The final score was obtained by adding the individual scores. The Table shows the distribution of faeces in a series of 45 cases (Connell et al., 1964). It will be seen that the right colon was heavily loaded more frequently than any other part of the colon. The rectosigmoid is also an important storage area of the colon.

\section{TABLE}

Faecal Shadows seen on Straight X-ray of the Abdomen in 45 'Normal' Subjects (percentages)

\begin{tabular}{|c|c|c|c|}
\hline & \\
\hline & - or + & + or ++ & +++ or ++++ \\
\hline Right & $13 \cdot 3$ & $64 \cdot 4$ & $22 \cdot 2$ \\
\hline Transverse & $60 \cdot 0$ & $40 \cdot 0$ & 0.0 \\
\hline Left & $5 \mathrm{I} \cdot \mathrm{I}$ & 44.4 & 4.4 \\
\hline Rectosigmoid & $42 \cdot 2$ & $5 \mathrm{I} \cdot \mathrm{I}$ & $6 \cdot 7$ \\
\hline
\end{tabular}

3. The Movements of the Colon. Radiologically the colon appears to be an inactive organ, but as early as 1935 Barclay described the active contractions of the haustra which resulted in alternate contraction and relaxation at any one site.

Recently there have been a number of papers describing the intraluminal pressure changes from the normal colon (Spriggs et al., I95I; Chaudhary \& Truelove, I96I; Connell, I96Ia). Most of these studies refer to the sigmoid colon and a clear picture of the activity of the colon has emerged from these reports. 
Figure $\mathrm{I}$ is a typical record of intraluminal pressures recorded simultaneously from points $25 \mathrm{~cm}$., $20 \mathrm{~cm}$. and $15 \mathrm{~cm}$. respectively from the anus. Two features are of particular importance. The colon, far from being an inactive organ, is contracting for a high proportion of the time of recording. Figures vary according to the method of recording used, but activities of between I3 per cent. and 5I per cent. of the time of analysis have been recorded in different series.

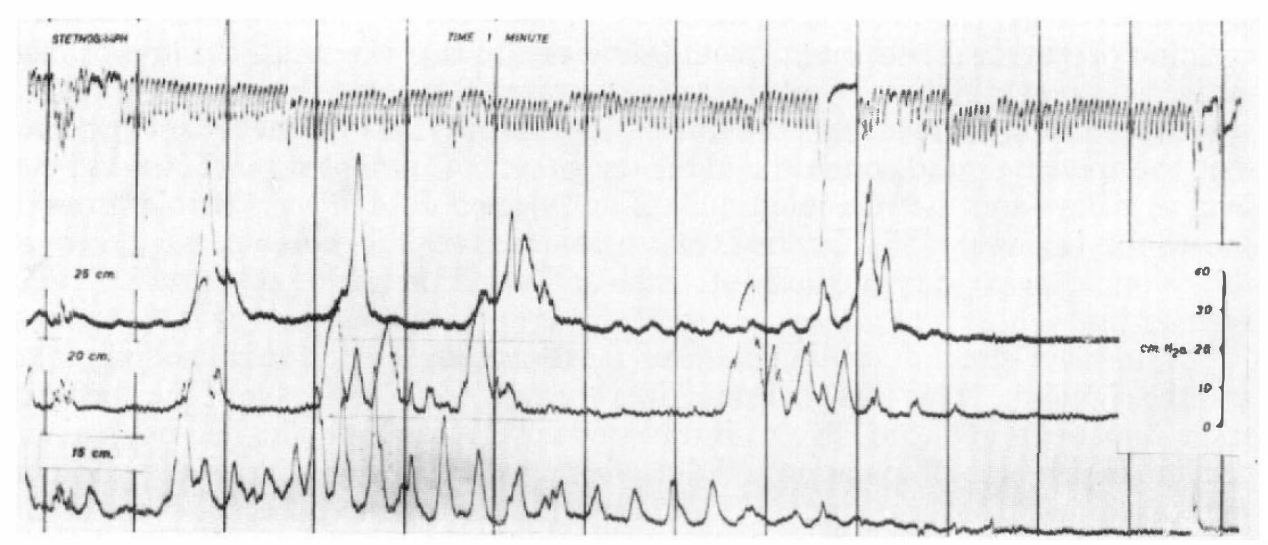

FIG. I

Intraluminal pressures recorded from the pelvic colon showing independent segmental activity. In this and subsequent records vertical lines indicate one minute intervals. Simultaneous records from 25,20 and $15 \mathrm{~cm}$. from the anus.

The second point of note is that records from neighbouring areas of the colon recorded simultaneously are dissimilar. The only satisfactory interpretation of this universal finding is that the activity of the colon is normally of an independent segmenting nature. Peristaltic waves, which might be interpreted as moving faeces over a length of colon, are rarely seen. Radiological studies in this field are notoriously difficult to perform due to the brief period available for study and the difficulty of quantitation of observation, but such studies as have been reported confirm this interpretation of intraluminal pressure records (Ritchie, Ardran \& Truelove, I962; Dellar \& Wangel, 1965).

The normal movements of the colon, then, tend to move the content in a to-and-fro motion. It follows that these waves are not propulsive in the normal sense and when they occur they do not indicate flow in the colon but resistance to flow. Indeed, consideration of the mechanics of intraluminal pressure recording demands that for a rise in pressure to be recorded there must be not only a change in the volume of the segment in which the recording point is placed but also a resistance to the escape of content from that segment. Records of intraluminal pressures should be regarded not as indices of propulsive activity but of the peripheral resistance of the colon.

Confirmation that this is so has been obtained by use of radio telemetering capsules. These capsules, which are ingestible and pass freely along the alimentary tract, record not only pressure but can be adapted to give an index of movement also. This arises from the fact that the signal from a capsule varies both with its 
distance and its axial rotation relative to a fixed aerial. Any movement of the capsule thus can be detected by a change in its signal strength. In records from the lumen of the sigmoid colon using a radio pill, there may be marked pressure activity while there is hardly any change in the signal strength indicating no major movement of the capsule confirming that the movements of the colon mainly delay forward movement rather than facilitate it.

How then does the colon move its content forward? It is essential that the peripheral resistance should be withdrawn before movement can occur. If this should happen and segmentation ceases, very little force is required to move faeces forward. The forward force could be provided by gravity or even the filling of the caecum from the terminal ileum. From time to time lengths of the colon contract forcibly, squeezing out the content of that section-the so-called mass movement described by Hertz (1907). In the absence of peripheral resistance the mass movement may translate faeces over considerable lengths of the colon.

4. Defaecation. It is beyond the scope of this paper to discuss in full the complex mechanism resulting in defaecation. Much valuable work has been reported recently relating to the mechanisms of anal sensation and anal relaxation. It is probable, however, that in the normal subject, anal mechanisms represent merely the last and relatively weak line of defence providing faecal continence. Successful defaecation involves both motor and sensory mechanisms. The sensory stimulus is probably distension over a length of the sigmoid colon and upper rectum. It has been shown in man that distension of the sigmoid results in changes in the motor activity in the region of the distending stimulus and that this response is a reflex requiring the integrity of the lumbo-sacral cord (Connell, Frankel \& Guttmann, I963).

The preliminary motor activity of defaecation is an inhibition of segmentation reducing peripheral resistance and so allowing the bolus to move forward. If the subject is in the erect position this movement may occur under the influence of gravity. Subsequently a single peristaltic wave passes along the colon and rectum sweeping it clean.

We are now in a position to consider physiological aberrations leading to constipation.

(a) The possibility exists that insufficient bulk is discharged into the caecum each day due to dietary irregularity. The caecum, with its great capacity for storage and concentration of the faeces, passes them on only at infrequent intervals resulting in infrequent bowel action.

(b) Segmental overactivity results in excessive peripheral resistance and prevents the onward passage of faeces. In a proportion of patients with severe constipation segmental activity is not reduced. Taking a group of constipated persons as a whole, activity was recorded 52 per cent. of the time as compared with 48 per cent. in normal subjects (Connell, 1962). Figure 3 is a record from a patient who is constipated. The rapid frequency and more constant nature of the activity should be compared with the normal record of Figure I. This is probably true 'spastic' constipation and results not only in infrequent defaecation but also the passage of small hard scyballae-so-called rabbit stools.

Patients with destruction of the lumbo-sacral segments of the spinal cord 
have an exaggeration of the segmental activity of the recto-sigmoid colon. Not only is the duration of activity greater, but the frequency of the waves tends to be very irregular (Connell et al., I963). It seems likely that this inco-ordinate bowel action must contribute to the severe constipation suffered by these subjects.

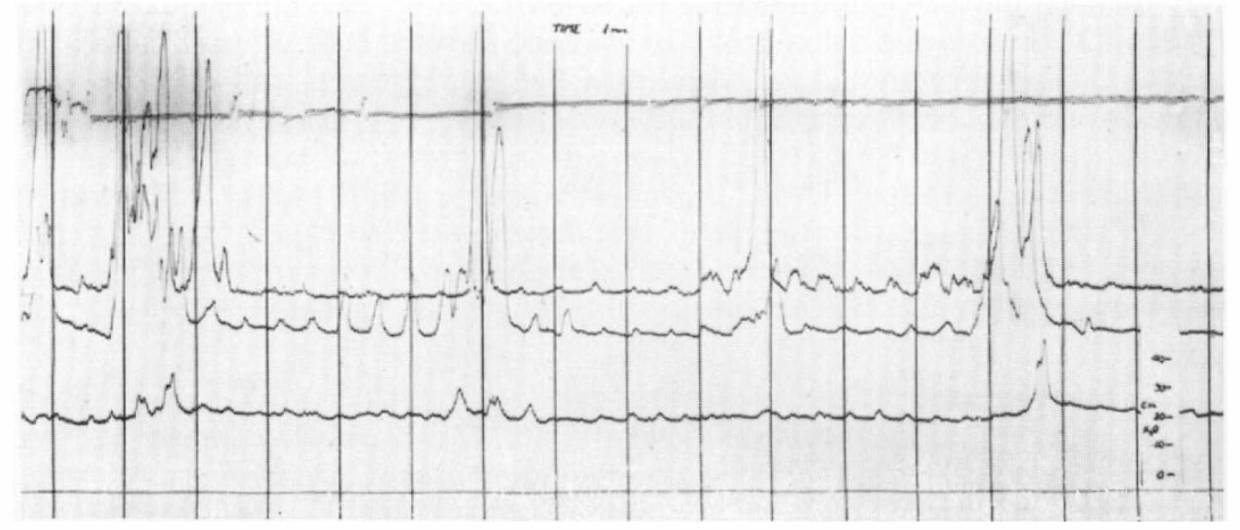

FIG. 2

Intraluminal pressure in the sigmoid colon in a constipated subject indicating considerable colonic muscular activity.

(c) In a small proportion of constipated subjects there is virtually no activity on pressure recording. In this case the constipation is not due to excessive peripheral resistance but to complete absence of all colonic movement. The result is that faeces accumulate in the atonic colon so that radiologically the picture is that of a megacolon. This picture is sometimes found in children who have megacolon with apparently normal ganglia. It occurs with some frequency in the senile. It may also develop in persons who have subjected themselves to prolonged overpurgation.

In some of these subjects no activity occurs even after injection of parasympatho-mimetic agents, but a proportion who have no obvious resting activity respond to parasympathetic stimulation. The lower trace in Figure 3 shows the absence of activity recorded from a young person with an acquired megacolon. The upper trace shows the activity generated following injection of prostigmine (Connell, I96Ib). Patients who respond well to subcutaneous prostigmine usually have a fair clinical response to neostigmine given orally.

(d) Disturbances of the defaecation mechanisms are a major cause of constipation with patients in neurological lesions. This may be due to sensory loss resulting in the absence of the call to stool. The result is the social embarrassment of being unaware that defaecation has occurred. In the patient with an established transection of the cervical or upper thoracic cord the defaecation reflexes are normal but the absence of sensation means that all voluntary control over the time or place of defaecation may be lost.

Sensory diminution in the aged is probably an important factor in the occurrence of faecal impaction which is a major problem in geriatric practice. 
Motor loss is in many ways more serious. In the patient with motor abnormalities of the sacral segments, defaecation is difficult. The normal response of the colon to distension is lost so that although relaxation of the haustra occasionally occurs allowing some entry of faeces into the rectum or even through the anus, the normal peristaltic wave fails to follow and defaecation is incomplete. There is a very real danger in this situation of progressive accumulation of faeces resulting in impaction.
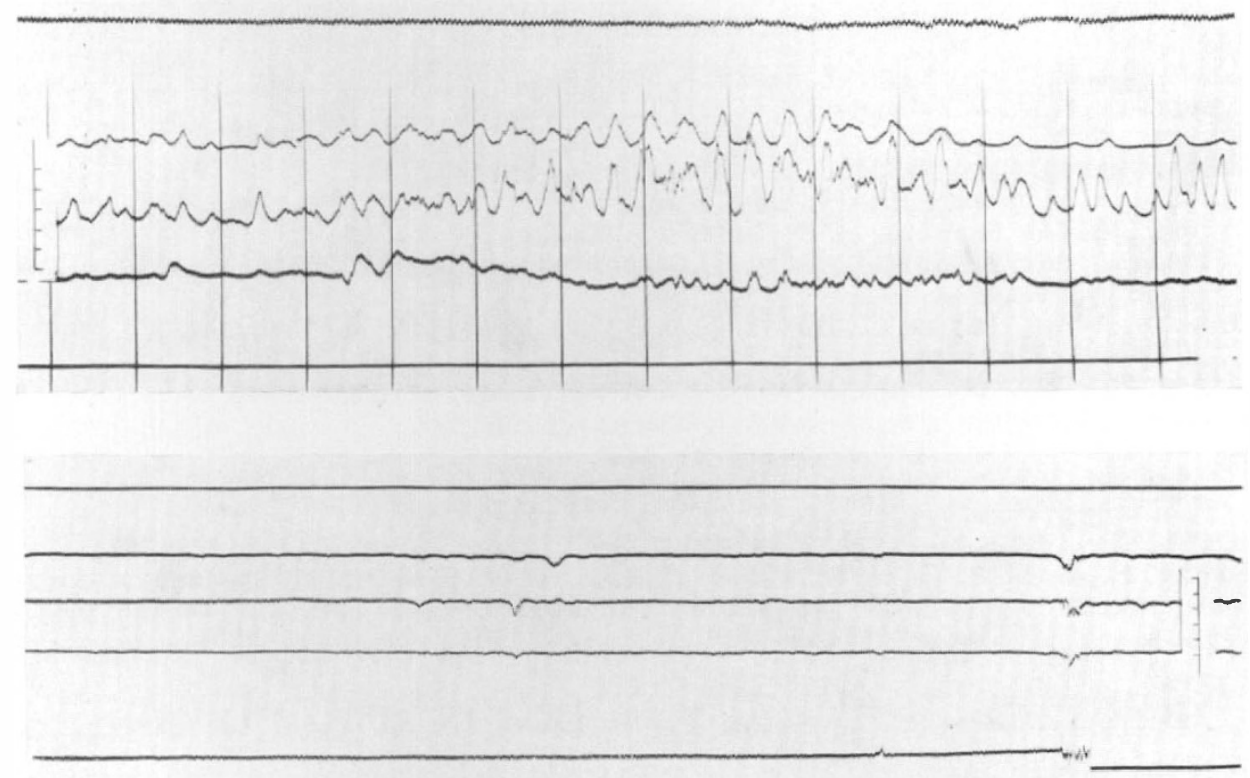

FIG. 3

Intraluminal pressures from the sigmoid colon in a patient with a megacolon. (a) Under basal conditions (lower series). (b) After injection of prostigmine $0.75 \mathrm{mg}$. S.C. (upper series).

The brief review indicates that constipation is a symptom complex resulting from a number of deviations from normal physiological mechanisms. It is important to understand the nature of the lesion involved and in severe cases full investigation is well rewarded as it permits the institution of logical effective therapy.

\section{SUMMARY}

A definition of constipation based on a survey of a normal population is attempted. The mechanism of normal colonic motility and, in particular, its independent segmenting activity are stressed. Constipation is seen to result from any of a number of mechanisms including:

(I) Inadequate bulk being presented to the distal colon.

(2) Hyperactivity of the segmenting mechanisms. 
(3) Exhaustion of the colonic musculature.

(4) Disturbance of the defaecation reflexes.

In normal adults the most common causes are those relating to the overactivity of the segmenting movements of the distal colon but a small number of persons have a true atonic constipation. In paraplegic patients, particularly those with lesions of the lumbar sacral cord, there is not only disturbance of the defaecation reflexes but probably hypersegmentation as well.

\title{
REFERENCES
}

BARClay, A. E. (1935). Brit. F. Radiol. 8, 625.

Chaudhary, N. A. \& Truelove, S. C. (I96I). Gastroenterology, 40, I.

ConNell, A. M. (1961a). Gut, 2, 175.

Connell, A. M. (196Ib). Proc. Roy. Soc. Med. 54, I2.

ConNell, A. M. (1962). Gut. 3, 342 .

Connell, A. M., Frankel, H. \& Guttmann, L. (1963). Paraplegia, I, 98.

Connell, A. M., Lennard Jones, J. E. \& Madanagopalan, N. (1964). Proc. Roy. Soc. Med. 57, 894 .

Connell, A. M., Hilton, C., Irvine, G., Lennard Jones, J. E. \& Misiewicz, J. J. (i965). Brit. med. F. 2, 1095.

DelleR, D. J. \& WANGEL, A. G. (I965). Gastroenterology, 48, 45.

Hansky, J. \& ConNell, A. M. (1962). Gut, 3, 187.

HerTz, A. F. (1907). Guy's Hosp. Rep. 6r, 389.

Keele, C. A. \& Neil, E. (196i). Samson Wright's Applied Physiology. London: Oxford University Press.

Ritchie, J. A., Ardran, G. M. \& Truelove, S. C. (I962). Gastroenterology, 43, 643.

Spriggs, E. A., Code, C. F., Bargen, J. A., Curtiss, R. K. \& Hightower, N. C. (I95i). Gastroenterology, 19, 480 .

\section{DISORDERS OF BOWEL FUNCTION IN SPINAL LESIONS}

\author{
By Dr. Volkmar Paeslack \\ Heidelberg, Germany \\ Spinal Centre, Orthopedic Unizersity Clinic
}

PARALYSIS of the bladder and bowels is expected in association with the diagnosis of paraplegia. Failure of the sympathetic nervous system is the part of the picture of spinal lesions which differentiates them from cerebral or peripheral nerve lesions. Although for this reason the urinary tract is automatically carefully watched nowadays, the bowel function is regarded as of less importance. Exact control of stomach and bowels is necessary if one wants to avoid severe complications during clinical treatment and for satisfactory social rehabilitation.

In every spinal lesion it is necessary to investigate the state of the digestive system. This will vary according to the level and extent of the lesion, the length of time the patient has been paralysed, the presence of complications, previous disorders, the age of the patient, and many other factors.

Certain special neuro-pathological points should be taken into consideration:

(I) The destruction of sympathetic innervation of the stomach and intestinal tract.

(2) The degree of paralysis of the abdominal muscles, the pelvic floor, and the external anal sphincter. 